\title{
STRENGTH AND STIFFNESS OF MECHANICALLY JOINTED CLT PANELS LOADED BY SHEAR IN PLANE
}

\author{
Lukáš Velebil, Petr Kuklík \\ Czech Technical University in Prague \\ Czech Republic
}

(Received December 20i9)

\begin{abstract}
This article is focused on research into the racking strength and stiffness of mechanically jointed cross laminated timber shear walls considering the influence of fasteners between the layers of boards on the stiffness of panels. The work includes an experimental analysis and analytical model. The experimental analysis included tests of the shear wall panels, tests of the specimens to determine the stiffness at the joint of the layers and material tests. The analytical model based on the component method allows the determination of the racking strength and horizontal displacement of the shear wall in dependence on the number of layers and the number of fasteners in the joint of layers, parameters of the anchorage to the substructure and applied external load. The outputs of the numerical model and the results of the experiments agree relatively well. The largest relative displacement error is $18 \%$.
\end{abstract}

KEYWORDS: Cross laminated timber (CLT), wall panels, racking strength, racking stiffness, fasteners, component method.

\section{INTRODUCTION}

Massive plate construction systems made of cross laminated timber are becoming more and more used for multi-storey construction. There is a European product standard, EN 16351 (2015), but it is still necessary to develop technical standards that would give designers the basis for designing structures from this product. The research of glued CLT has been the subject of activity of scientific teams for many years (Mestek et al. 2008, Schickhofer et al. 2010, Bogensperger et al. 2010, Gagnon and Pirvu 2011, Kreuzinger and Sieder 2013, Brandner et al. 2017, Song et al. 2019, Wie et al. 2020). The most common method of joining layers is by all-over gluing. An alternative to the gluing process is the usage of mechanical fasteners. Nowadays, only the method for surfaces from mutually flexible jointed layers (DIN 1052 2008) can be used to design this system. However, this method does not take into account the effect of wall anchoring or the plasticity of the fasteners, and the empirically determined values of the slip modulus are 
higher than the values measured during the tests. General relationships of the theory of elasticity and models of torsionally rigid joints describing the distribution of forces and stresses in the joints in relation to the arrangement of fasteners (Racher 1995) can be used to create a more suitable model. The verification of the racking strength of wall panels is therefore based on the assessment of the shear strengths in the joints of the layers. Blaß and Görlacher (2002) and Jöbstl et al. (2004) investigated the strength and stiffness in torsional shear of a glued joint between perpendicularly oriented boards. Flaig and Meyer (2014) focused on the creation of a test method for a more accurate determination of the slip modulus in glued joints.

The racking strength and stiffness of shear walls are significantly influenced by the type of anchoring to the substructure, which must ensure the transmission of tensile and shear forces induced by the horizontal load in plane of the wall (Fragiacomo et al. 2011, Hummel et al. 2013, Gavric et al. 2015). Jára (2018) dealt with the issue of anchoring sandwich shear wall panels of wooden buildings. The analytical model compiled using a component method is included in this research. With increasing horizontal loads on the wall, the model considers the shift of the centre of rotation in the panel anchorage and the related gradual activation of tensile anchors. The method of components in research of structure was also used by Wald et al. (2000), Brühl and Kuhlmann (2012) and Sabatka et al. (2014).

This paper presents the results of experimental analysis and the description of an analytical model for determining the racking strength and stiffness of wall panels made of mechanically jointed cross-laminated timber.

\section{MATERIAL AND METHODS}

\section{Experimental analysis}

Three types of tests were performed in the experimental analysis. The first type was the test of the racking strength and stiffness of the wall panel. The rotation of the joints between the layers and thus the shear deformation of the whole panel depends on the rigidity of the lamella connection. The second type was therefore the test for determining the torsional stiffness of the layers' joint and the slip modulus of fasteners in dependence on the number of layers and the number of fasteners in the joint. The third type were material tests to determine the modulus of elasticity, bending strength and density of wooden boards.

The EN 594 (2011) was used to perform and evaluate the racking strength and stiffness of the wall panel. The applied horizontal and vertical loads as well as horizontal and vertical displacements of the specimen were recorded during the tests. Three specimens with dimensions of $3000 \times 2520 \times 81 \mathrm{~mm}$ were used. The panels consisted of three layers of boards $27 \mathrm{~mm}$ thick and $170 \mathrm{~mm}$ wide. Two galvanized screws $5 \times 80 \mathrm{~mm}$ were used to join the layers in each board crossing. The characteristic values of a $5 \%$ quantile of the stiffness $K_{s, k}$ and the load-bearing capacity $F_{v, k}$ were determined from the results of the experiments.

The tests for the determination of stiffness in the joints of the layers were carried out according to the EN 26891 (1991). The specimens were placed in steel test equipment during the experiment. The design of the test equipment is based on tests to determine the slip modulus in the joint of glued boards (Meyer and Flaig 2014). The value of the applied loading force and mutual rotation of the boards were recorded during the experiments. Five series of test specimens with five identical specimens in each series were used to determine the joint stiffness. The specimens consisted of boards with dimensions of $170 \times 27 \times 500 \mathrm{~mm}$ joined together by screws $5 \times 80 \mathrm{~mm}$. The number of lamellae in the specimens and the number of screws in each shear plane between the lamellae are listed in Tab. 1 . 
Tab. 1: Experimental program for the determination of stiffness in joints of layers.

\begin{tabular}{|l|c|c|c|c|c|}
\hline Test series & A_2L & B_2LS & C_3L & D_3LS & E_5L \\
\hline Number of lamellae in each specimen & 2 & 2 & 3 & 3 & 5 \\
\hline Number of screws in each shear plane & 2 & 4 & 2 & 4 & 2 \\
\hline
\end{tabular}

The maximum torsional moment $M_{\max , \text { exp }}$, the torsional stiffness of the layers' joint $K_{r, \text { ser }, i, e x p}$, the slip modulus of the fasteners $K_{\text {ser, }, \text { exp }}$ and the maximum load per one cut of the fastener $F_{M, i, \max , \exp }$ were determined from the measured data.

All test specimens were conditioned in a standard laboratory environment. Three basic parameters were evaluated to determine wood material properties: modulus of elasticity parallel to grain, $5 \%$ quantile of density and characteristic value of bending strength. The dynamic modulus of elasticity was determined by a non-destructive ultrasonic method. The static modulus of elasticity was then determined from the dynamic modulus of elasticity. To determine the bending strength, the boards were subjected to a 4-point bending test. The material characteristics of the Würth screws were taken from the ETA-11/0190 (2013).

The output of the layers' joint stiffness tests and the material tests were the values used as input data for the analytical model. The data obtained from the shear wall tests were used for the validation of the analytical model.

\section{Analytical model}

The shear wall was divided into a system of five components to create the model: screw joint of layers in shear $\left(a_{1}\right)$, vertical boards in compression parallel to the grain $\left(a_{2}\right)$, bottom wall plate in compression perpendicular to the grain $\left(a_{3}\right)$, bolt joint of the anchor and the panel in shear $\left(a_{4}\right)$ and base of the steel anchor in bending $\left(a_{5}\right)$. The stiffness and load-bearing capacity are determined for each component in dependence on its geometric arrangement, material characteristics and type of stress. The racking strength of the wall corresponds to the component with the lowest load-bearing capacity. To determine the displacement in plane of the wall, the components are assembled into a corresponding relationship, taking into account the applied load and the geometric arrangement of the wall. The displacement at the top of the wall is composed from the displacement including the stiffness effect of the connection between the layers $\left(a_{1}\right)$ and from the displacement caused by the rotation of panel in its anchorage $\left(a_{2}-a_{5}\right)$. Due to the free rotation of the lamella ends and also due to the low stiffness of the joint between the layers in relation to the bending and shear stiffness of the lamellae, the wall displacement caused by the bending and shear stress of the lamellae is negligible and was not considered in the analytical model.

\section{RESULTS AND DISCUSSION}

\section{Tests of shear walls}

A mutual torsional displacement of the board between the layers due to the grain embedment by fasteners, the deformation of the tensile panel anchor and the grain embedment by the bolts connecting the panel to the anchor occurred during the loading of panels. The evaluation of the racking strength and stiffness of shear wall panels is presented in Tab. 2. 
Tab. 2: Racking strength and stiffness of shear wall panels.

\begin{tabular}{|c|c|c|c|c|c|c|}
\hline Test & $K_{s, \exp }$ & $K_{s, a v g}$ & $K_{s, k}$ & $F_{v, \text { max }}$ & $F_{v, a v g}$ & $F_{v, k}$ \\
\hline specimen & $\left(\mathrm{N} \cdot \mathrm{mm}^{-1}\right)$ & $\left(\mathrm{N} \cdot \mathrm{mm}^{-1}\right)$ & $\left(\mathrm{N} \cdot \mathrm{mm}^{-1}\right)$ & $(\mathrm{kN})$ & $(\mathrm{kN})$ & $(\mathrm{kN})$ \\
\hline S_1 & 510 & \multirow{3}{*}{582} & \multirow{3}{*}{358} & 33.65 & \multirow{3}{*}{32.13} & \multirow{3}{*}{26.20} \\
\hline S_2 & 651 & & & 30.06 & & \\
\hline S_3 & 585 & & & 32.67 & & \\
\hline
\end{tabular}

\section{Tests of layers' joint}

The curves describing the dependences of the joint rotation on the torsional moment are presented in Fig. 1. The values of the torsional stiffness and load bearing capacity of the joints increase in proportion to the increasing number of shear planes and the number of fasteners. If the dependences of the load and displacement of the screws are related to one cut of fastener, the curves of the dependences are almost identical for all series (Fig. 2). The summary of the mean values of load-bearing capacities and stiffnesses of joints is shown in Tab. 3.

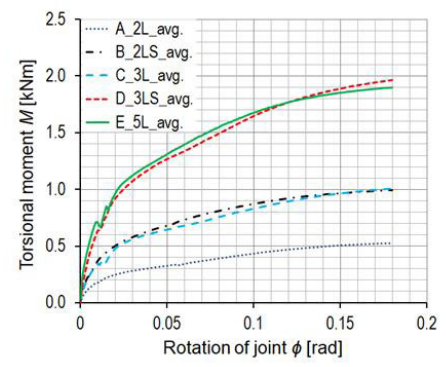

Fig. 1: Comparison of joint rotation to torsional Fig. 2: Comparison of displacement and load moment dependence.

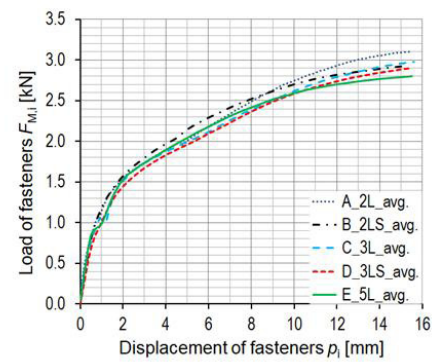

dependencies of the fastener.

Tab. 3: Summary of load-bearing capacities and stiffnesses of test series $A-E$.

\begin{tabular}{|c|c|c|c|c|}
\hline Test series & $M_{\max , \exp }(\mathrm{kNm})$ & $F_{M, i, \max , \exp }(\mathrm{N})$ & $K_{r, \text { ser, }, i, \exp }$ & $K_{\text {ser, }, i, \exp }\left(\mathrm{N} \cdot \mathrm{mm}^{-1}\right)$ \\
\hline A_2L & 0.52 & 3083.79 & 17.90 & 1242.87 \\
\hline B_2LS & 0.99 & 2911.33 & 30.93 & 1074.20 \\
\hline C_3L & 1.00 & 2947.86 & 24.22 & 841.05 \\
\hline D_3LS & 1.95 & 2873.39 & 51.42 & 892.80 \\
\hline E_5L & 1.89 & 2786.07 & 52.95 & 919.29 \\
\hline
\end{tabular}

\section{Analytical model}

To determine the displacement of the panel affected by the stiffness in the joint of the layers $\left(a_{1}\right)$, the dependence between the horizontal load of the panel $F_{v}$ and the force acting on one cut of the fastener is found. The stiffness of component $a_{1}$ can be expressed as:

$$
K_{\mathrm{a} 1, \mathrm{ser}}=\frac{K_{\mathrm{ser}} \cdot r^{2} \cdot m \cdot n \cdot a_{0} \cdot a_{90}}{h_{\mathrm{CLT}}{ }^{2}}=\frac{K_{\mathrm{rser,CLT}} \cdot a_{0} \cdot a_{90}}{h_{\mathrm{CLT}}{ }^{2}}
$$

where: $K_{\text {ser }}$ is the slip modulus of the fastener, $r$ is the distance of the fastener from the centre of the joint rotation, $m$ is the number of the shear planes, $n$ is the number of fasteners, $a_{0}$ is the 
number of boards along the panel length, $a_{90}$ is the number of boards along the panel height, hCLT is the height of the panel and $K_{r, s e r, C L T}$ is the torsional stiffness of the layers' joint.

To determine the stiffness of the compressed components $a_{2}$ and $a_{3}$, the elastic behavior and dependence for normal stress and relative elongation were considered. The stiffness of components $a_{2}$ and $a_{3}$ can be expressed for the triangular stress distribution in the compressed zone of the wall anchor as:

$$
K_{\mathrm{a} 2(3)}=\frac{2 \cdot E_{\mathrm{mean}, \mathrm{a} 2(3)} \cdot d_{1 \mathrm{am}, 0} \cdot a \cdot p}{h_{\mathrm{aka} 2(3)}}
$$

where: $E_{\text {mean,a2(3) }}$ is the modulus of elasticity parallel to the grain $\left(a_{2}\right)$ and perpendicular to the grain $\left(a_{3}\right), d_{\text {lam }, 0}$ is the thickness of the board, $a$ is the length of the compressed zone, $p$ is the reduction factor of the loaded area and $h_{a k, a 2(3)}$ is the active length of the elements $a_{2}$ and $a_{3}$.

Components $a_{2}$ and $a_{3}$ are considered as lines and the stiffnesses are therefore apply to $1 \mathrm{~mm}$ of component length. Components $a_{4}$ and $a_{5}$ are considered as points. The stiffness of the component $a_{4}$ is determined using the $K_{\text {ser }}$ slip module:

$$
K_{a, 4}=K_{s e r} \cdot n \cdot m
$$

where: $n$ is the number of bolts in the joint and $\mathrm{m}$ is the number of shear planes.

The component $a_{5}$ is considered as a pair of symmetrical consoles, loaded by forces at the free ends. The stiffness of a component is expressed as:

$$
K_{a, 5}=\frac{2 \cdot 3 \cdot E \cdot I}{L^{3}}
$$

where: $E$ is the modulus of elasticity in tension of the steel, $I$ is the moment of inertia of the console and $L$ is the length of the console.

The panel rotation depends on the rotational stiffness $K_{\alpha, C L T}$ including the influence of the stiffness of components $a_{2}-a_{5}$. The connection of components $a_{2}$ and $a_{3}$ in the compression zone as well as $a_{4}$ and $a_{5}$ in the tension zone is considered to be serial. Within the rotational stiffness $K_{\alpha, C L T}$, the components in the compression and tension zone are in parallel connection. The stiffness in the compression zone $K_{c}$ is expressed as:

$$
\frac{1}{K_{\mathrm{c}}}=\frac{1}{K_{\mathrm{a} 2}}+\frac{1}{K_{\mathrm{a} 3}}
$$

The stiffness of the tensile anchor $K_{t, i}$, taking into account the displacement $\delta_{0}$ given by the tolerance of the bolt hole and the tensile force in the anchor $F_{t, i}$, is based on the relation:

$$
\frac{1}{K_{\mathrm{ti}}}=\frac{1}{K_{\mathrm{a} 4, \mathrm{i}}}+\frac{1}{K_{\mathrm{a} 5, \mathrm{i}}}+\frac{1}{\frac{F_{\mathrm{tij}}}{\delta_{0}}}
$$

The rotational stiffness $K_{\alpha, C L T}$ is determined as:

$$
K_{\mathrm{a}, \mathrm{CLT}}=K_{\mathrm{c}} \cdot \frac{a^{3}}{3}+\sum_{i=1}^{n} K_{\mathrm{ti}} \cdot s_{\mathrm{ri}}^{2}
$$

where: $n$ is the number of anchors loaded in tension and $s t, i$ is the distance of the anchor from the center of wall rotation. 
The function describing the course of the horizontal displacement at the top of the wall was divided into three intervals defined by the values of the horizontal load:

$$
v_{(\mathrm{Fv}, \mathrm{F} \mathrm{g}, \mathrm{a})}=\left\{\begin{aligned}
\frac{F_{\mathrm{v}}}{K_{\mathrm{a} 1, \mathrm{ser}}}, & 0<F_{\mathrm{v}} \leq F_{\mathrm{v}, 0} \\
\frac{F_{\mathrm{v}}}{K_{\mathrm{a} 1, \mathrm{ser}}}+\frac{M_{\mathrm{ed}, \mathrm{CLT}} \cdot h_{\mathrm{CLT}}}{K_{\mathrm{a}, \mathrm{CLT}}}, & F_{\mathrm{v}, 0}<F_{\mathrm{v}} \leq \frac{2}{3} F_{\mathrm{v}, \max } \\
\frac{2}{\frac{3}{3} F_{\mathrm{v}, \max }}+\frac{F_{\mathrm{v}}-\frac{2}{3} F_{\mathrm{v}, \max }}{K_{\mathrm{a} 1, \mathrm{ser}}}+\frac{M_{\mathrm{ed}, \mathrm{CLT}} \cdot h_{\mathrm{CLT}}}{K_{\mathrm{a}, \mathrm{CLT}}}, & \frac{2}{3} F_{\mathrm{v}, \max }<F_{\mathrm{v}} \leq F_{\mathrm{v}, \mathrm{ma}}
\end{aligned}\right.
$$

The first interval describes the state when the whole bottom wall plate is stressed in compression due to the vertical load on the panel. The second interval defines the state when the horizontal limit load $F_{v, o}$ compensating the effect of vertical loading is exceeded and the outermost anchor of the panel begins to be stressed by tension. Within the third interval, the stiffness of the layers' joint is reduced and the slip modulus of the fasteners $K_{s e r}$ is replaced by the slip modulus $K_{u}$, determined as $K_{u}=2 / 3 K_{\text {ser }}$ After reaching the horizontal limit load and activating the rotational stiffness, the wall displacement is determined based on a set of equations, including the vertical and moment equilibrium condition and the relationship for the horizontal displacement at the top of the panel. The vertical lifts of the panel $u$, the horizontal displacement of the panel $\mathrm{v}$ and the length of the compression zone $a$ are unknown.

The torsional moments and shear forces are distributed uniformly over the fasteners, similar to glued CLT (Blaß and Flaig 2012). The load of one cut of the fastener is based on the vector sum of the forces from the torsional moment $F_{M}$ and from the shear force $F_{O}$. Depending on the shear resistance of one cut of the fastener in the vertical and horizontal lamella $F_{v, R}$, the load-bearing capacity of the panel $F_{V, a 1, \max }$ can be determined as:

$$
F_{\mathrm{v}, \mathrm{a} 1 \text {, } \max }=\min \left\{\begin{array}{c}
\frac{F_{\mathrm{v}, \mathrm{R}} \cdot a_{0} \cdot a_{90} \cdot m \cdot n \cdot r^{2}}{\left(2 a_{\mathrm{n}}^{2} \cdot h_{\mathrm{CLT}}{ }^{2}+2 h_{\mathrm{CLT}} \cdot a_{\mathrm{n}} \cdot r^{2}+r^{4}\right)^{1 / 2}} \\
\frac{F_{\mathrm{v}, \mathrm{R}} \cdot a_{0} \cdot a_{90} \cdot m \cdot n \cdot r^{2} \cdot b_{\mathrm{CLT}}}{\left(2 a_{\mathrm{n}}{ }^{2} \cdot h_{\mathrm{CLT}}{ }^{2} \cdot b_{\mathrm{CLT}}{ }^{2}+2 h_{\mathrm{CLT}} \cdot a_{\mathrm{n}} \cdot b_{\mathrm{CLT}} \cdot r^{2}+h_{\mathrm{CLT}}{ }^{2} \cdot r^{4}\right)^{1 / 2}}
\end{array}\right.
$$

where: $a_{n}$ is the distance of the fasteners from the center of joint rotation in the $\mathrm{x}$-axis and $b_{C L T}$ is panel width.

Components $a_{2}$ and $a_{3}$ do not affect the load-bearing capacity of the wall, because after the local exceeding of the compressive strength of the board, the shear wall is able to withstand the increasing horizontal load. The load-bearing capacity of component $a_{4}$ is given by the shear resistance of the bolts. The load-bearing capacity of component $a_{5}$ is based on the moment of resistance of the steel anchor base. The maximum tensile force in the anchor must be less than or equal to the maximum load capacity of components $a_{4}$ and $a_{5}$ :

$$
K_{\mathrm{t}} \cdot \alpha_{\mathrm{t}} \cdot s_{\mathrm{ti}} \leq \min \left\{F_{\mathrm{a} 4 \text { max }} ; F_{\mathrm{a} 5, \max }\right\}=\min \left\{m \cdot n_{\mathrm{r}} \cdot n_{\mathrm{ef}} \cdot F_{\mathrm{V}, \mathrm{a}, \mathrm{R},} ; \frac{2 W_{\mathrm{y}} \cdot f_{\mathrm{y}}}{L}\right\}
$$

where: $a_{t}$ is the angle of panel rotation, $n_{r}$ is the number of rows of fasteners, $n_{e f}$ is the effective number of fasteners in a row, $F_{v, a 4, R}$ is the shear resistance of one cut of the fastener, $W_{y}$ is the cross-sectional modulus of the anchor base and $f_{y}$ is the yield strength of steel.

\section{Comparison of experimental results with analytical model outputs}

The test data of wall panels were averaged for a clearer graphical comparison of the results. The comparison of the displacement curves is shown in Fig. 3. 

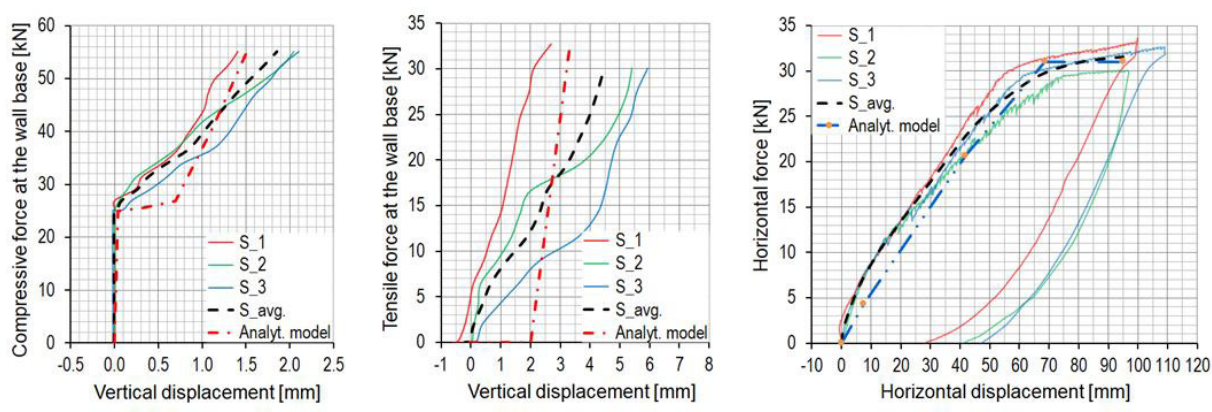

Fig. 3: Comparison of experimental results with analytical model outputs at the end of the compression zone of anchorage (left), at the end of the tensile zone of anchorage (middle) and at the top of the wall (right).

The largest absolute difference in horizontal displacements at the top of the panel is $12.5 \mathrm{~mm}$ (relative error of 18\%). The absolute difference of the maximum resistances is $1.1 \mathrm{kN}$ (relative error of 3.5\%). By comparing the experimental data with the outputs of method for surfaces from mutually flexible jointed layers (DIN 1052 2008), the largest absolute difference in displacements of $47 \mathrm{~mm}(313 \%)$ and resistances of $2.3 \mathrm{kN}(7.7 \%)$ is obtained. If the slip modulus of the fasteners from the standard is replaced by stiffness obtained from the tests of layers' joints, the maximum absolute difference in displacements is $11 \mathrm{~mm}(16 \%)$.

\section{CONCLUSIONS}

The analytical model for determining the load-bearing capacity and deformation of the shear wall made of mechanically jointed cross-laminated timber was compiled and the obtained data were validated using the results of the tests of three wall panels. The maximum relative difference in deformations is $18 \%$ and resistances is $3.5 \%$.

The deformation in the wall plane is most significantly affected by the stiffness of the contact between the layers. Based on the performed stiffness tests in the joint of layers, it can be stated that the values of torsional stiffness and load-bearing capacity of joints increase in proportion to the increasing number of shear planes and the number of fasteners. The differences in the average values of the slip modulus of the fasteners are up to $9 \%$ for the series of specimens corresponding to the common layup of wall panels.

\section{ACKNOWLEDGMENTS}

This work has been supported by the project TE02000077 Smart Regions - Buildings and Settlements Information Modelling, Technology and Infrastructure for Sustainable Development and by the project COST LD15077 Mechanically jointed cross laminated timber (CLT). 


\section{REFERENCES}

1. Bogensperger, T., Moosbrugger, T., Silly, G., 2010: Verification of CLT-plates under loads in plane. In: Proceedings of the 11th conference WCTE 2010 (ed. Ceccotti, A.). National Research Council, Trentino Pp 1-9.

2. Blaß, H.J., Flaig, M. 2012: Stabförmige Bauteile aus Brettsperrholz. KIT Scientific Publishing, Karlsruhe, 171 pp.

3. Blaß, H.J., Görlacher, R., 2002: Zum Trag- und Verformungsverhalten von Brettsperrholzelementen bei Beanspruchung in Plattenebene. Bauen mit Holz 104(11): 34-41.

4. Brandner, R., Dietsch, P., Dröscher, J., Schulte-Wrede, M., Kreuzinger, H., Sieder, M., 2017: Cross laminated timber (CLT) diaphragms under shear: Test configuration, properties and design. Construction and Building Materials 147: 312-327.

5. Brühl, F., Kuhlmann, U., 2012: Connection ductility in timber structures considering the moment-rotation behavior. In: Proceedings of the 12th conference WCTE 2012. Auckland Pp 136-145.

6. DIN 1052, 2008: Entwurf, Berechnung und Bemessung von Holzbauwerken - Allgemeine Bemessungsregeln und Bemessungsregeln für den Hochbau.

7. EN 16351, 2015: Timber structures. Cross laminated timber. Requirements.

8. EN 26891, 1991: Timber structures. Joints made with mechanical fasteners. General principles for the determination of strength and deformation characteristics.

9. EN 594, 2011: Timber structures. Test methods. Racking strength and stiffness of timber frame wall panels.

10. ETA 11/0190, 2013: Self-tapping screws for use in timber constructions.

11. Fragiacomo, M., Dujic, B., Sustersic, I., 2011: Elastic and ductile design of multi-storey crosslam massive wooden buildings under seismic actions. Engineering Structures 33(11): 3043-3053.

12. Gagnon, S., Pirvu, C., 2011: CLT handbook: Cross-laminated timber. Vancouver, British Columbia: FPInnovations, $380 \mathrm{pp}$.

13. Gavric, I., Fragiacomo, M., Ceccotti, A., 2015: Cyclic behaviour of typical metal connectors for cross-laminated (CLT) structures. Materials and Structures. 48(6): 1841-1857.

14. Hummel, J., Flatscher, G., Seim, W., Schickhofer, G., 2013: CLT wall elements under cyclic loading - Details for anchorage and connection. In: COST Action FP1004 (ed. Harris, R., Ringhofer, A., Schickhofer, G.). University of Bath, Bath, Pp 152-165.

15. Jára, R., 2018: Anchoring of load-bearing sandwich panels of timber buildings. Dissertation. Czech Technical University in Prague, Prague, 90 pp.

16. Jöbstl, R.A., Bogensperger, T., Schickhofer, G., Jeitler, G., 2004: Mechanical behaviour of two orthogonally glued boards. In: Proceedings of the 8th conference WCTE 2004. Finnish Association of Civil Engineers. Helsinki, Pp 357-364.

17. Kreuzinger, H., Sieder, M., 2013: Basic test method for valuation of shear strength of cross laminated timber. Bautechnik 90(5): 314-316.

18. Mestek, P., Kreuzinger, H., Winter, S., 2008: Design of Cross Laminated Timber (CLT). In: Proceedings of the 10th conference WCTE 2008. TU Munich, Munich, Pp. 156-163.

19. Meyer, N., Flaig, M., 2014: A new test configuration to determine the slip modulus of connections between crosswise bonded boards. In: COST FP1004 (ed. Schober, K.). University of Bath, Bath, Pp 77-84. 
20. Racher, P., 1995: Moment-resisting joints. In: Timber engineering - Principles for design (ed. Blaß, H.J., Sandhaas, C.). KIT Scientific Publishing, Karlsruhe, Pp 491-508.

21. Sabatka, L., Wald, F., Kabeláč, J., Gödrich, L., Navrátil, J., 2014: Component based finite element model of structural connections. In: Proceedings of the $12^{\text {th }}$ International Conference on Steel, Space and Composite Structures. Prague, Pp 337-344.

22. Schickhofer, G., Bogensperger, T., Moosbrugger, T., 2010: BSP Handbuch: HolzMassivbauweise in Brettsperrholz. Verlag der TU Graz. Graz, 440 pp.

23. Song, Y.J., Lee, I.H., Hong, S.I., 2019: Evaluation of horizontal shear performance of larch CLT walls according to the edge connection shape. Wood Research 64(2): 213-222.

24. Wald, F., Mareš, J., Sokol, Z., Drdácký, M., 2000: Component method for historical timber joints. In: The Paramount Role of Joints into the Reliable Response of Structures (eds. Banitopoulos, C.C., Wald, F.). NATO Science Series. Dordrecht, Pp 417-425.

25. Wie, P., Wang, B.J., Li, Z., Ju, R., 2020: Development of cross-laminated timber (CLT) products from stress graded Canadian hem-fir. Wood Research 65(2): 335-346.

*Lukáš Velebil, Petr Kuklík

Czech Technical University in Prague

Faculty of Civil Engineering

TháKurova 2077/7

i66 29 Prague

Czech Republic

*Corresponding author: lukas.velebil@crut.cz 
